\title{
EDUCAÇÃO AMBIENTAL: A MÚSICA COMO MEIO PARA EXPRESSAR AS NOÇÕES DE MEIO AMBIENTE
}

Camila Fernandes Duarte ${ }^{1}$

\author{
Bettina Heerdt ${ }^{2}$ \\ Angelita Machado Soldan ${ }^{3}$ \\ Maristela Procidonio ${ }^{4}$ \\ Milena Mattoso da Costa 5 \\ Luan Cesar Grofoski ${ }^{6}$
}

Resumo: As noções de meio ambiente são mediadas pela realidade social, e a música é um meio de expressar sentimentos, emoções e conhecimentos em relação a uma determinada realidade. Neste artigo temos por objetivo analisar as noções de meio ambiente que estão explícitas nas composições musicais elaboradas por estudantes do ensino médio. Foram elaboradas unidades de contexto e de registro para a análise de 21 letras de músicas. Foi possível identificar noções de meio ambiente naturalista, antropocêntrica, complexa, de destruição, de problema/solução e reducionista. Por meio da música os estudantes expressaram pensamentos, sentimentos e conhecimentos em relação ao meio ambiente, de uma maneira espontânea e criativa.

Palavras-chave: Composições Musicais; Ensino Médio; Noções de Meio Ambiente.

1 Bióloga assessora da Secretária de Meio Ambiente - Município Guarapuava. E-mail: camibio13@hotmail.com

2 Professora do Departamento de Métodos e Técnicas de Ensino - Universidade Estadual de Ponta Grossa (UEPG). E-mail: bettina_heerdt@yahoo.com.br

3 Bióloga da Secretaria de Meio Ambiente - Município Guarapuava. E-mail: angelita_machado@hotmail.com

${ }^{4}$ Bióloga da Secretaria de Meio Ambiente - Município Guarapuava. E-mail: maris_proci@yahoo.com.br

5 Técnica em Meio Ambiente. E-mail: milenamattosodacosta@hotmail.com

${ }^{6}$ Acadêmico do curso de Ciências Biológicas pela Faculdade Guairacá. E-mail: luangrofoski@gmail.com 


\section{Introdução}

A preocupação com as questões ambientais continua sendo legítima e atual, uma vez que, segundo Morin (2011), vivemos num mundo em crise de valores. Essa crise possui suas raízes na ciência moderna, que dissemina um pensamento dicotômico e dualista de certo/errado, natureza/cultura, corpo/mente, razão/emoção. Nesse pensamento, nos afastamos da natureza como se fossemos indivíduos somente culturais e a natureza estivesse posta para nos servir, perdemos nesse processo o elo entre humanidade e natureza. Leff (2006) descreve a crise ambiental não somente como crise ecológica, mas como crise de razão, considerando as problemáticas ambientais fundamentalmente como problemáticas de conhecimento.

Loureiro (2004, p.16) expõe a necessidade da construção de "um novo patamar societário e de existência integrada às demais espécies vivas e em comunhão com o mundo", fala da necessidade de superação das formas de alienação que propiciam a dicotomia sociedade/natureza. Segundo o autor, essa alienação é produto

[...] de um longo processo histórico de expropriação dos meios de produção e reprodução sociais da maioria. Tal expropriação implica não só não ter-se os chamados meios materiais de existência, mas também os meios simbólicos dados fundamentalmente pelo processo educacional, ambos negados a milhões de brasileiros e a bilhões de pessoas no planeta.

A Educação Ambiental Crítica contribui com o resgate de valores essenciais para a cidadania, com um olhar integrado das relações entre seres humanos e a natureza, e entre seres humanos e seus semelhantes (GUIMARÃES, 2004). Brügger (2004) e Reigota (2006) concordam que um passo inicial é a correta construção do significado de meio ambiente. Para esses autores, o conceito de meio ambiente deve considerar os aspectos naturais e sociais, observando todas as relações entre os fatores biológicos, sociais, físicos, econômicos, culturais e históricos.

O termo meio ambiente é adotado e usado de modo polissêmico como símbolo de natureza, ambientalismo, educação ambiental, ecologia, entre outros, não havendo um consenso do seu significado, mesmo na comunidade científica. O meio científico, por sua vez, não ficou imune ao processo de popularização desse termo. Podemos perceber isso em alguns discursos que querem congregar tudo em nome do ambiental, e algumas vezes com enfoque reducionista (AIRES; BASTOS, 2011).

Sauvé (2003) descreve o ambiente como uma realidade socialmente construída; sendo assim, é difícil defini-lo de forma precisa, abrangente e consensual. Diante disso, a autora considera que, ao invés de se propor uma única definição do ambiente, é interessante explorar suas várias representações, como podemos analisar na Figura 1.

revista brasileira educação ambiental 


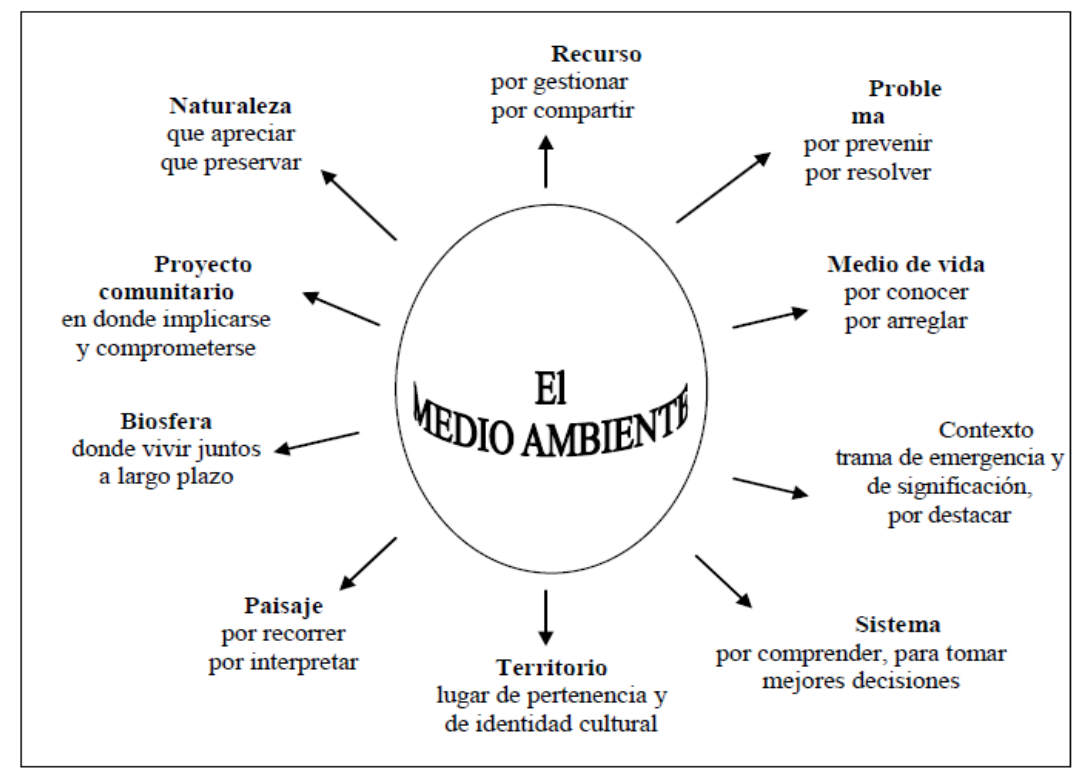

Figura 1: Tipologia de representações de Meio Ambiente Fonte: Sauvé (2001 apud SAUVÉ, 2003).

Muitos são os autores que, em seus estudos, preocupam-se em reconhecer as noções de meio ambiente e educação ambiental de professores (MAGALHÃES; TOMANIK, 2013; LIMA; OLIVEIRA, 2011; FONSECA; OLIVEIRA, 2011; NETO; AMARAL, 2011; IARED; OLIVEIRA, 2001) e estudantes (GARRIDO; MEIRELLES, 2014; AIRES; BASTOS, 2011; MARTINHO; TALAMONI; 2007). Essas pesquisas, de um modo geral, ainda mostram uma noção de meio ambiente reducionista, naturalista, e de uma educação ambiental simplista e superficial, fato esse que está relacionado à crise de conhecimento citada por Leff (2006). Essa questão é preocupante, uma vez que a escola é considerada como um espaço privilegiado para a reflexão da temática ambiental e a possível construção de uma noção integrada do mundo, no tempo e no espaço (DIAS, 2004).

As metodologias de coleta de dados utilizadas nas pesquisas de percepções, representações e/ou noções de meio ambiente e educação ambiental são diversificadas. Usam-se entrevistas, questionários, construção de mapas mentais, representações gráficas, o que é válido, pois se for empregada apenas uma forma de coletar os dados pode-se restringir a noção de meio ambiente do indivíduo. Nesta pesquisa optamos por analisar letras de músicas que foram escritas por estudantes do ensino médio que participaram de um festival da canção ecológica. Compreendemos que a linguagem musical pode representar o modo como o indivíduo que compôs a música percebe o ambiente.

A pesquisa de Nunes (2005) busca analisar a influência da música nas 
[...] a linguagem musical, apesar de possuir certas analogias, não pode substituir ou ser comparada literalmente a linguagem verbal. Por ser uma linguagem não objetiva ou não referencial, a música não pode ser traduzida como na linguagem verbal, mas nem por isso perde sua capacidade de representação, simbolização e comunicação (NUNES, 2005, p.48).

Além disso, Nunes (2005, p. 50) destaca que "a função comunicativa da música está intrinsicamente relacionada a seu papel social, sendo necessária sempre uma relação sistemática entre ela e o contexto social que a produz e a recebe".

Ao compreender o sujeito como constituído e constituinte do contexto social do qual emana, "é possível qualificar a música como uma forma de comunicação, de linguagem, pois por meio do significado que ela carrega e da relação com o contexto social no qual está inserida, ela possibilita aos sujeitos a construção de múltiplos sentidos singulares e coletivos" (MAHEIRIE, 2003, p.148).

Tanto para o ouvinte quanto para o compositor, a música está relacionada à afetividade, que contempla as emoções e os sentimentos. Podese dizer que a afetividade envolve as relações humanas consideradas espontâneas. A música é, portanto, "uma linguagem reflexivo-afetiva" (MAHEIRIE, 2003, p. 148); "é uma expressão do pensamento afetivo e sua função é simbólica, posto que revela e traduz uma época, um fato, ou outro objeto qualquer" (p. 150).

É importante ressaltar que é da realidade que se extraem os elementos que compõem a imaginação. De acordo com Maheirie (2003), quanto mais ricas são as experiências de vida do sujeito, maior é o material que ele tem disponível para compor.

Se pensarmos desse modo, os sujeitos mediados pela realidade social, ao criarem as letras das músicas, partiram de um contexto social em que os elementos relacionados às problemáticas ambientais foram construídos durante a vida desses sujeitos pela escola, meios de comunicação, família, amigos, entre outros, refletindo na maneira como eles apresentam as letras musicais. Nesse sentido, a hipótese de pesquisa é a de que as letras das músicas inscritas em um festival ecológico refletem as noções de meio ambiente de seus compositores. Por conseguinte, neste artigo temos por objetivo analisar as noções relacionadas ao meio ambiente que estão explícitas nas composições musicais elaboradas para o festival da canção ecológica do ano de 2014. 


\section{Metodologia}

A metodologia utilizada é de natureza qualitativa. Na concepção de Bogdan e Biklen (1994), e de Lüdke e André (1986), esse tipo de investigação apresenta uma natureza descritiva, na qual os pesquisadores têm um interesse maior no processo e nos seus significados do que nos resultados ou produtos.

Os dados analisados são letras de 21 músicas, que foram nomeadas de L01 a L21, provenientes da 15aㅡ edição do Festival da Canção Ecológica que ocorreu no ano de 2014, promovido pela Secretaria de Meio Ambiente do munícipio de Guarapuava. Esse festival conta com um regulamento que prevê que todas as canções inscritas sejam inéditas, e que os compositores, autores e cantores representem apenas a instituição de ensino em que estejam matriculados. Participaram do evento 21 colégios (cada um com uma música, conforme o regulamento), sendo quatro instituições particulares e 17 do ensino público, e um total de 49 estudantes envolvidos diretamente no processo.

Visando a alcançar o objetivo proposto, para a análise dos dados utilizamos a análise de conteúdo temática categorial em um sentido amplo, a qual pode ser definida como "[...] um conjunto de técnicas de análise das comunicações [...]", cujo propósito é obter, "[...] por procedimentos, sistemáticos e objetivos de descrição do conteúdo das mensagens, indicadores (quantitativos ou não) que permitam a inferência de conhecimentos relativos às condições de produção/recepção (variáveis inferidas) destas mensagens" (BARDIN, 2004, p. 37).

Foram elaboradas unidades de registro (UR) que podem ser um tema, uma palavra ou uma frase. O texto é recortado pelas UR, sendo "[...] a unidade de significação a codificar e corresponde ao segmento do conteúdo a considerar como unidade de base, visando à categorização e a contagem frequencial" (BARDIN, 2004, p. 98).

Para a análise dos conteúdos das músicas também foram elaboradas UR, com base no referencial teórico de Sauvé $(2003,2005)$ e Reigota (2002). Após a análise foi necessária a elaboração de uma unidade de registro emergente (URE).

UR1.1 - Naturalista: para agrupar os fragmentos textuais que contenham registros que descrevem o ambiente pelos seus aspectos naturais (bióticos e abióticos) e, também, por suas noções espaciais (habitat dos seres vivos). O ser humano é mero espectador, apreciador.

UR1.2 - Antropocêntrica: para agrupar os fragmentos textuais que contenham registros que descrevem a utilidade dos recursos naturais (como recurso) e a preservação para a sobrevivência e bem-estar do ser humano.

UR1.3 - Socioambiental: para agrupar os fragmentos textuais que contenham registros que descrevem o meio ambiente de modo a evidenciar as relações de reciprocidade existentes entre o ambiente natural e a sociedade (questões políticas, sociais, econômicas e/ou culturais). 
UR 1.4 - Destruição: para agrupar os fragmentos textuais que contenham registros que descrevem o meio ambiente destruído pelo ser humano.

UR 1.5 - Problema/solução: para agrupar os fragmentos textuais que contenham registros que descrevem o meio ambiente com problemas e mostram algumas soluções ou mencionam a preservação para solucionar os problemas.

URE 1.6 - Reducionista: para agrupar os fragmentos textuais que contenham registros que descrevem soluções simplistas para a resolução dos problemas ambientais.

A seguir serão apresentados os resultados, as inferências e as interpretações realizadas. No momento em que apresentamos as análises, é conveniente enfatizar que essa não é a única interpretação possível, pois está permeada pelas escolhas teóricas e metodológicas da presente pesquisa.

\section{Resultados, inferências e interpretações}

As noções de MA podem ser concebidas de diversas maneiras, sendo que, tradicionalmente, as principais concepções constituem as representações produto de um dualismo que transita entre a noção antropocêntrica e a noção naturalista. Atualmente o que se busca é aprimorar essas noções para uma noção complexa, em que se perceba a existência de uma rede de relações que não apenas as naturais, mas também as sociais e as culturais, para que assim se possa compreender e conhecer melhor essa realidade multifacetada.

$\mathrm{Na}$ Tabela 1 são apresentadas as unidades de registro referentes ao conteúdo das letras das músicas analisadas e os fragmentos textuais que exemplificam as unidades elaboradas, bem como a frequência relativa das respostas. Foram retiradas das letras as repetições dos refrãos.

Tabela 1: Fragmentos textuais dos conteúdos das letras das músicas

\begin{tabular}{|c|c|c|}
\hline $\begin{array}{l}\text { Unidades de } \\
\text { Registro (UR) }\end{array}$ & Fragmentos textuais & $\begin{array}{l}\text { Frequência } \\
\text { relativa (\%) }\end{array}$ \\
\hline \multirow[t]{2}{*}{$\begin{array}{l}\text { UR } 1.1 \text { - } \\
\text { Naturalista }\end{array}$} & $\begin{array}{l}\text { "Estava sentado no quintal lá de casa. De repente o João de } \\
\text { Barro veio conversar. As borboletas sentaram no canto do } \\
\text { banco. Para ouvir a história que ele tinha que contar. Ele } \\
\text { falava de um coral escondido nas matas. E os pássaros felizes } \\
\text { todos a cantar. Quando a noite caiu os vagalumes chegaram. } \\
\text { Com as cigarras e o violão para me acompanhar. E a música } \\
\text { linda se ouviu no ar. É o som suave da natureza. A beleza das } \\
\text { matas em harmonia. Todo esse encanto que contagia [...]. } \\
\text { (L01, fragmentado em 1.2) }\end{array}$ & $\begin{array}{l}8,7 \% \\
\quad(02 \\
\text { fragmentos } \\
\text { textuais) }\end{array}$ \\
\hline & $\begin{array}{l}\text { "[...] A ecologia é a relação entre os seres vivos, que atua } \\
\text { neste mundo neste paraíso [...] [...] vamos acabar com essa } \\
\text { história de extinção, para que espécies de animais não } \\
\text { acabem jamais, e pra encerrar vamos pela natureza lutar". } \\
\text { (L05, fragmentado 1.2) }\end{array}$ & \\
\hline
\end{tabular}


...continuação.

\begin{tabular}{|c|c|c|}
\hline $\begin{array}{l}\text { Unidades de } \\
\text { Registro (UR) }\end{array}$ & Fragmentos textuais & $\begin{array}{l}\text { Frequência } \\
\text { relativa (\%) }\end{array}$ \\
\hline \multirow[t]{5}{*}{$\begin{array}{c}\text { UR } 1.2 \text { - } \\
\text { Antropocêntrica }\end{array}$} & $\begin{array}{l}\text { "Estamos chegando para mencionar como o mundo é, e para } \\
\text { declarar que somente nós podemos mudar, vamos reciclar e o } \\
\text { lixo vai para seu lugar, para que um ar puro possamos } \\
\text { respirar. A poluição gera situação pra nossa nação, a } \\
\text { devastação também causa grande preocupação. Então vamos } \\
\text { lutar pelo trabalho de nossas mãos, diminuindo um pouco } \\
\text { nossa exploração. Aqui nesta Terra temos a áqua pra } \\
\text { sustentar, economizando ela nunca vai nos faltar. Vamos } \\
\text { anunciar para o mundo inteiro se alertar, que a água é vida e } \\
\text { ela pode acabar. [...] Hoje o objetivo é não destruir e ter } \\
\text { consciência e assim, garantir nossa sobrevivência. Veja ao } \\
\text { nosso redor o mundo em que vivemos, quanto agrotóxicos na } \\
\text { plantação hoje vemos. Então levantando a nossa voz fazendo } \\
\text { nossa parte, e tudo que pudermos faremos antes que seja } \\
\text { tarde. Aqui nesta pátria somos brasileiros e não abrimos[...]". } \\
\text { (L05 fragmentado em UR.1.1) }\end{array}$ & \multirow[t]{5}{*}{$\begin{array}{l}(05 \\
\text { fragmentos } \\
\text { textuais })\end{array}$} \\
\hline & $\begin{array}{l}\text { [...] Consome tudo em sua frente sem querer saber. Que o } \\
\text { amanhã já pode não amanhecer. Meu nome é natureza. Eu } \\
\text { sou a natureza. Florestas, cachoeiras, praia, sol e mar. Tudo o } \\
\text { que construí pra tu poder usar [...]. (L08, fragmentado em UR } \\
1.4)\end{array}$ & \\
\hline & $\begin{array}{l}\text { "Humanidade. Sem dor, sem dó, sem piedade. Subsistente. } \\
\text { Natureza imponente, quanto menos tu entende, mais sustenta } \\
\text { tua mente. Matar para vestir. Se acabar para existir. Perceba } \\
\text { que o que está em jogo é simplesmente sua vida, sua água e } \\
\text { comida. Fonte de vida. Só há uma solução, só uma saída. } \\
\text { Preservação. Preserve a natureza, essa é. Essa é a solução". } \\
\text { (L14) }\end{array}$ & \\
\hline & $\begin{array}{l}\text { "Em uma rua de flores. Encontrei o meu amor. Debaixo de } \\
\text { uma árvore. Foi onde tudo começou. Frutas e verduras. Era } \\
\text { tudo natural. E as crianças brincavam no quintal. O tempo se } \\
\text { passou. Tudo mudou. Carros, indústrias e ruas. O homem } \\
\text { criou. Tirar o necessário. Sem exagerar. Usar a natureza. Com } \\
\text { consciência. E preservar. O nosso lar. No centro da cidade. A } \\
\text { fumaça se espalhou. As flores acabaram. Em cidades se } \\
\text { tornaram. Agora o que nos resta. É preservar. A natureza que } \\
\text { é o nosso lar". (L15) }\end{array}$ & \\
\hline & $\begin{array}{l}\text { [...] No momento me veio uma triste lembrança. Não podemos } \\
\text { destruir a nossa herança. Presença é virtude destruir nunca } \\
\text { mais. É cuidar daquilo que Deus nos traz". (L01, fragmentado } \\
\text { em UR 1.1). }\end{array}$ & \\
\hline
\end{tabular}

Continua... 
...continuação.

\begin{tabular}{|c|c|c|}
\hline $\begin{array}{l}\text { Unidades de } \\
\text { Registro (UR) }\end{array}$ & Fragmentos textuais & $\begin{array}{l}\text { Frequência } \\
\text { relativa (\%) }\end{array}$ \\
\hline $\begin{array}{l}\text { UR } 1.3 \text { - } \\
\text { Complexa }\end{array}$ & $\begin{array}{l}\text { "Os rios poluídos não vamos tomar, as terras inférteis não } \\
\text { vamos plantar, pra que exportar tanto os nossos produtos, } \\
\text { esgotando assim todos nossos recursos. Acidente nuclear } \\
\text { grande contaminação, por centenas de anos como foi no } \\
\text { Japão. Chernobyl foi triste, Fukushima também, destruiu } \\
\text { florestas, e humanos também. Centros urbanos, segregação } \\
\text { social, lixos não renováveis, problema ambiental. Acidente } \\
\text { nuclear grande contaminação, por centenas de anos como foi } \\
\text { no Japão. Tanta poluição, difícil respirar, muitas fábricas e } \\
\text { carros poluindo o ar". (L11) }\end{array}$ & $\begin{array}{c}21,8 \% \\
\\
\quad \text { (05 } \\
\text { fragmentos } \\
\text { textuais) }\end{array}$ \\
\hline & $\begin{array}{l}\text { "Vejo a violência unificada, na ignorância. Vejo os falsos } \\
\text { surdos que só ouvem a voz da intolerância. As águas sujas } \\
\text { gritam, inundam. Os animais perdidos, em conflitos, não } \\
\text { sabem para onde vão. Há uma canção, um som, uma melodia. } \\
\text { O planeta grita. Vejo a raça humana afogada em seu próprio } \\
\text { lixo. Pessoas pobres, sujas, sem comida, tratadas como } \\
\text { bichos. A terra todo dia sem saída, e as pessoas dizem não. } \\
\text { Pra vida, natureza, segurança e educação. Há uma canção, } \\
\text { um som, uma melodia. O planeta grita. Escute. Salve-me!" } \\
\text { (L06) }\end{array}$ & \\
\hline & $\begin{array}{l}\text { "Pensei num ritmo bem bom pra cantar. Pra expor de um jeito } \\
\text { bem legal. Decidi que tem que ser esta vanera. A luta por um } \\
\text { mundo com equilíbrio ambiental. Não ta fácil garantir tanto } \\
\text { recurso. Pra manter esse consumo exagerado. Então convido } \\
\text { você meu amigo. A consumir somente o que tem necessitado. } \\
\text { Vem, vem, vem, vem dançar. Faça sua parte de um jeito bem } \\
\text { legal. Seja cidadão que pensa no futuro. Ajude o nosso mundo } \\
\text { a ter equilíbrio ambiental. Eu te pergunto porque tanto lixo. Se } \\
\text { não recicla e não separa material. Se ajudar nessa separação. } \\
\text { Posso dizer: estamos sendo racional. Você pode fazer a sua } \\
\text { parte. Não desperdice água tratada com bobagem. Pense na } \\
\text { água que utiliza em sua casa. Use água da chuva pra lavar } \\
\text { sua garagem. Agora quero alertar pra um assunto. Que me } \\
\text { traz grande descontentamento. O homem faz sem culpa } \\
\text { nenhuma. E ninguém é punido pelo desmatamento. Eu não } \\
\text { penso só no meu pampa gaúcho. Penso na Amazônia, } \\
\text { Cerrado e Pantanal. Na Mata Atlântica, Araucária e Caatinga. } \\
\text { Dando lugar pra soja e milharal. Nas estradas não cabem } \\
\text { tanto carro. E a gente não consegue respirar. E a queima de } \\
\text { óleo diesel e gasolina. Os pulmões reclamam a poluição do ar. } \\
\text { Tem animais invadindo as cidades. A culpa é nossa por } \\
\text { acabar com a floresta. Preservar, recuperar e não poluir. É a } \\
\text { melhor atitude ambiental que nos resta". (L07) }\end{array}$ & \\
\hline
\end{tabular}

Revbea, São Paulo, V. 11, № 4: 60-77, 2016.

revista brasileira 
...continuação.

\begin{tabular}{|c|c|c|}
\hline $\begin{array}{l}\text { Unidades de } \\
\text { Registro (UR) }\end{array}$ & Fragmentos textuais & $\begin{array}{l}\text { Frequência } \\
\text { relativa (\%) }\end{array}$ \\
\hline & $\begin{array}{l}\text { "Não quero cantar uma canção careta. Não quero dizer a você } \\
\text { e ao planeta: Que a vida vai acabar. Quero apenas, nesse } \\
\text { momento, cantar, contar ao mundo o meu tormento. Falar de } \\
\text { coisas que eu aprendi: Que precisamos reeducar, pra ser feliz! } \\
\text { Você quer gastar só por gastar, acha bonito e vai comprar, } \\
\text { não se preocupa com ninguém não. Nem quer saber se } \\
\text { precisa ou não. E vai comprando e vai comprando. E vai } \\
\text { juntando coisas e coisas. Nem se dá conta que. Que não } \\
\text { precisa de tanta tralha para viver. Enquanto isso o meu } \\
\text { vizinho, aquele menino bem magrinho. Vai procurar lá no meu } \\
\text { lixo, um pouco de pão pra ele comer. Enquanto eu compro o } \\
\text { que não preciso. O meu vizinho morre de fome. Mas eu não } \\
\text { ligo. Vi na TV que tudo é moda, e pra ser chique tem que } \\
\text { comprar, Tem que usar o que o artista usa, Nem que eu não } \\
\text { goste da cor da blusa, Mas é a moda eu vou usar. A minha } \\
\text { vizinha, mãe da Clarinha, não tem dinheiro para a papinha, } \\
\text { Mas o cabelo tá com chapinha, agora é moda ela vai usar. } \\
\text { Que tanta tralha que você quer? Que tanta tralha que você } \\
\text { tem! Vai enchendo a sua vida de coisa boba sem razão. Vai! } \\
\text { Esvazie seu armário! Vai limpando sua consciência. Vai } \\
\text { gastando com moderação! Só compre se precisar. Só jogue } \\
\text { se não prestar. Reutilize quando puder. Pra ser feliz basta ter } \\
\text { paz, não precisa gastar, gastar. Dizer não ao consumismo é } \\
\text { escolher vida melhor. Desapega desse consumo. Desapega } \\
\text { dessa ilusão. Que não traz paz. Que não traz pão. Que gera } \\
\text { guerra. Entre irmãos. Vamos deixar de ter demais, vamos } \\
\text { pensar em sermos mais, sermos aqueles que vão lutar, uma } \\
\text { luta justa para o planeta. Planeta meu e do meu vizinho, } \\
\text { aquele menino bem magrinho. Planeta da Dona Maria, da Mãe } \\
\text { da Clarinha, que precisamos reeducar". (Lo9). }\end{array}$ & \\
\hline & $\begin{array}{l}\text { "Assim que somos todos. Únicos não. A vida se torna } \\
\text { supérfluo. O progresso justifica a razão. Entre tempestades de } \\
\text { ideias. Futuro de interrogações. Petróleo, ódio, religiões. Por } \\
\text { isso entre no padrão. As custas da vida. Fome, feridas, ilusão. } \\
\text { Controle, descontrole. Entre tantos animais. Também somos. } \\
\text { Um dia à extinção. Raros, fatos, sombras. O futuro revendo o } \\
\text { passado. Desintegrado ao choro. Arrependido, antes } \\
\text { justificado. A volta sem volta talvez. O agora transformado. O } \\
\text { futuro estruturado. Que a sabedoria fez". (L10) }\end{array}$ & \\
\hline
\end{tabular}

Continua... 
...continuação.

\begin{tabular}{|c|c|c|}
\hline $\begin{array}{l}\text { Unidades de } \\
\text { Registro (UR) }\end{array}$ & Fragmentos textuais & $\begin{array}{l}\text { Frequência } \\
\text { relativa (\%) }\end{array}$ \\
\hline \multirow[t]{3}{*}{$\begin{array}{c}\text { UR } 1.4 \text { - } \\
\text { Destruição }\end{array}$} & $\begin{array}{l}\text { "O homem se comporta como um micróbio. A inteligência se } \\
\text { tornou seu próprio ópio. [...] A grama verde, a sombra da } \\
\text { árvore fresquinha. Mas realmente a natureza humana é } \\
\text { mesquinha. Destrói tudo sem pensar nas consequências. } \\
\text { Dessa maneira eu vou entrar em decadência. Eu sou aquela } \\
\text { que você tira o petróleo. Constrói armas pra destruição e ódio. } \\
\text { Você não soube cuidar do que eu lhe emprestei. Eu sou a sua } \\
\text { mãe fui eu quem te criei. Meu nome é natureza. Consome } \\
\text { tudo em sua frente sem querer saber. Que o amanhã já pode } \\
\text { não amanhecer". (L08, fragmentado em UR 1.2). }\end{array}$ & \multirow[t]{3}{*}{$\begin{array}{l}(03 \\
\text { fragmentos } \\
\text { textuais) }\end{array}$} \\
\hline & $\begin{array}{l}\text { “Olhe para fora e me diga o que vê. Vejo árvores cortadas } \\
\text { sem poder se defender. Destruídas, e arrancadas do chão. } \\
\text { Muitas delas descartadas ou muitas vezes usadas em vão. } \\
\text { Rios poluídos, muita vida já não tem suas águas tão escuras } \\
\text { nada vale pra ninguém. Gases poluentes fazem nosso ar } \\
\text { pesar. E cada vez mais difícil vai ficar pra respirar. Se árvores } \\
\text { tivesse lágrimas e rios pudessem falar. Estaríamos nos } \\
\text { afogando e gritos iríamos escutar. Ouça o clamor da natureza. } \\
\text { Ajude ela a se levantar. Seja agora a esperança. Não deixe o } \\
\text { mundo se acabar. Pólos derretendo e a temperatura a subir. O } \\
\text { nível do mar aumentando tudo ele vai cobrir. Não vai ter pra } \\
\text { onde fugir. Não vai dar pra se esconder. E isso será o fim. Se } \\
\text { ninguém nada fazer". (L20) }\end{array}$ & \\
\hline & $\begin{array}{l}\text { "Tudo isso foi previsto mas ninguém quis acordar. Veja a boca } \\
\text { do precipício. Onde tudo vai acabar. O início do fim. As folhas } \\
\text { voam com o vento. Sentimento aflorar. O que resta é só } \\
\text { lamento. Não adianta mais chorar. O vento leva as feridas. } \\
\text { Que o homem lhe deixou a natureza em despedida. Triste } \\
\text { sente o rancor. As pessoas sabem que fizeram algo errado. A } \\
\text { culpa é fardo que vamos carregar. O homem destruiu. E não } \\
\text { dá pra consertar. A natureza se revolta, o fim vai chegar. O } \\
\text { vento leva as feridas. Que o homem lhe deixou. A natureza } \\
\text { em despedida. Triste sente o rancor. As pessoas sabem que } \\
\text { fizeram algo errado. A culpa é fardo que vamos carregar. } \\
\text { Agora me diga o que pensou. Se era besteira começou. A } \\
\text { natureza já não supera. Esse é o fim que nos espera". (L21) }\end{array}$ & \\
\hline
\end{tabular}


...continuação.

\begin{tabular}{|c|c|c|}
\hline $\begin{array}{l}\text { Unidades de } \\
\text { Registro (UR) }\end{array}$ & Fragmentos textuais & $\begin{array}{l}\text { Frequência } \\
\text { relativa (\%) }\end{array}$ \\
\hline \multirow[t]{4}{*}{$\begin{array}{c}\text { UR } 1.5 \text { - } \\
\text { Problema/solução }\end{array}$} & $\begin{array}{l}\text { "O que vai ser do mundo no futuro? Como vai ser a vida de } \\
\text { nossas crianças se não cuidarmos de nosso planeta? O que } \\
\text { hoje é amanhã pode não ser. Construímos esse mundo e } \\
\text { vivemos reclamando. Por ações que fizemos e deixamos de } \\
\text { fazer. Olhando em volta podemos ver. Os erros que gostamos } \\
\text { de cometer. Para termos um futuro melhor. Precisamos da sua } \\
\text { ajuda. Cada um de nós precisa fazer a sua parte. Recicle, } \\
\text { cuide da água. Cuide do ar, proteja a natureza. Ajude a } \\
\text { manter a vida. Para no futuro o sol ainda brilhar. O ar puro } \\
\text { está raro. O verde desbotado. No coração da mata, o rastro do } \\
\text { vazio. No coração do homem, a dureza do machado. Pense, } \\
\text { repense seus atos. Uma dor é inevitável. Quando na } \\
\text { lembrança. A floresta fizer parte". (L03) }\end{array}$ & \multirow[t]{3}{*}{$\begin{array}{l}\text { (07 } \\
\text { fragmentos } \\
\text { textuais) }\end{array}$} \\
\hline & $\begin{array}{l}\text { O que estamos pensando? O que estamos fazendo? A vida } \\
\text { consumindo. Muito lixo produzindo. É preciso refletir. Tá na } \\
\text { hora de mudar. Termos que interferir. E a natureza ajudar. } \\
\text { Não se pode respirar. Quando não é puro o ar. Acabar com a } \\
\text { poluição. Deve ser nossa missão. Da energia renovável. } \\
\text { Também tem que falar. Não é só de combustível. Que o } \\
\text { automóvel vai rodar. Viver é ser feliz. Amando a natureza. } \\
\text { Tornando-se aprendiz. Curtindo a sua beleza. Por que se for } \\
\text { assim. Será o nosso fim. Preservemos nosso meio. Não } \\
\text { podemos estar alheios. Vamos separar o lixo. Precisamos } \\
\text { reciclar. Proteger nossos bichos. Nem pensar em desmatar. } \\
\text { (L04) }\end{array}$ & \\
\hline & $\begin{array}{l}\text { "Não derrubem as nossas matas. Não poluam nossos rios. } \\
\text { Não nos mate de calor. Não espante nosso frio. Salvar o } \\
\text { planeta Terra. Não é batalha perdida. Vamos dar as nossas } \\
\text { mãos. Para salvar as nossas vidas. O homem está matando. } \\
\text { O mundo com suas mãos possuído de riqueza. E ganância } \\
\text { por dinheiro. E quem paga por tudo isso. E a mãe natureza. } \\
\text { Nossas matas grandiosas. E com tantos animais. Está se } \\
\text { tornando cenário. De muitos marginais. Nosso mundo está } \\
\text { morrendo. Com a dor da poluição. Temos que regar o verde. } \\
\text { Dentro do nosso coração". (L13) }\end{array}$ & \\
\hline & $\begin{array}{l}\text { "A poluição está aí. E se não preservar. O fim da Terra vai } \\
\text { chegar. As águas vão sumir. A poluição está aí. E o humano } \\
\text { vai ficar. Sem vida por aqui! Mas ainda está em tempo. De } \\
\text { rever cada atitude. Vamos repensar. Para que a nossa Terra } \\
\text { mude. Só basta ter vontade. E determinação. Sair do reclame. } \\
\text { E partir para a ação. As águas vão sumir. A poluição está aí. E } \\
\text { se não preservar. O fim da Terra vai chegar". (L16) }\end{array}$ & \\
\hline
\end{tabular}


...continuação.

\begin{tabular}{|c|c|c|}
\hline \multirow[t]{2}{*}{$\begin{array}{l}\text { Unidades de } \\
\text { Registro (UR) }\end{array}$} & Fragmentos textuais & \multirow[t]{2}{*}{$\begin{array}{l}\text { Frequência } \\
\text { relativa (\%) }\end{array}$} \\
\hline & $\begin{array}{l}\text { "Vamos pensar em algo diferente, sem exploração dessa } \\
\text { forma inconsequente do que o homem transformou em tribo } \\
\text { urbana pra satisfazer a ganância dessa gente. Que não sabe } \\
\text { usar de uma forma consciente sustentabilidade inteligente } \\
\text { inconformados com essas atitudes vamos mudar com nossa } \\
\text { juventude. Geração consciente que busca para um futuro, um } \\
\text { bom presente que quer mudar o mundo com pequenas } \\
\text { atitudes não como super-heróis, mas como adolescentes. Não } \\
\text { desmatar, mas sim plantar. Não poluir, mas sim deixar fluir. } \\
\text { Não acabar, mas sim recomeçar. Fazendo o melhor que } \\
\text { podemos dar". (L17) }\end{array}$ & \\
\hline & $\begin{array}{l}\text { "O homem chegou. Desmatou. Poluiu. O rio ele contaminou. } \\
\text { Na natureza interferiu. E a teia da vida. Quebrou. Na brisa do } \\
\text { mar. No verde da floresta. Me fez pensar que podemos. } \\
\text { Mudar. Se cada um fizer sua parte. O planeta podemos salvar. } \\
\text { É só conscientizar. Hoje vivemos em um tempo. Modernização } \\
\text { tudo está ficando. Novas indústrias estão crescendo e } \\
\text { causando. Muita poluição. O meio ambiente se modificou. O ar } \\
\text { que respiro também já mudou. É preciso conscientização. Pra } \\
\text { não afetar a próxima geração". (L18) }\end{array}$ & \\
\hline & $\begin{array}{l}\text { "Agora é hora de juntar toda a nação. Chamar amigos e vir } \\
\text { nessa missão. Todos juntos pela preservação. Por um mundo } \\
\text { melhor, sem poluição. Vamos nos unir. Agora é hora de } \\
\text { mudar. Para isso precisamos agir. E as pessoas conscientizar. } \\
\text { A mudança está em todos nós. Basta acreditarmos que somos } \\
\text { capazes. Venha conosco você não vai se arrepender. Em um } \\
\text { mundo melhor podemos viver. Devemos reciclar, preservar, } \\
\text { cultivar, transformar. Ainda ouvimos isso, porque já vivemos } \\
\text { nesse mundo sujo! Onde quem é a favor já não é mais. E } \\
\text { ainda destroem a terra de seus ancestrais. Falam daquilo que } \\
\text { fazem. E escondem tudo o que jamais farão!". (L19) }\end{array}$ & \\
\hline $\begin{array}{c}\text { URE - } 1.6 \\
\text { Reducionista }\end{array}$ & $\begin{array}{l}\text { "Reciclar é muito bom reciclar é importante todo mundo } \\
\text { colaborando com o meio ambiente reciclar é muito bom, } \\
\text { reciclar é bom demais, se todos ajudarem a gente pode mais. } \\
\text { Todos estão cansados de saber, que o lixo não deve se } \\
\text { misturar, por isso vamos lá galera vamos separar, com essa } \\
\text { nova ação vamos todos continuar. Reciclando e aprendendo, } \\
\text { daqui a pouco logo estão fazendo, qualquer tipo de material } \\
\text { então vamos lá galera preste bem atenção e ouça com muito } \\
\text { carinho a consequência da nação". (L12) }\end{array}$ & $\begin{array}{l}\text { (01 } \\
\text { fragmento } \\
\text { textual) }\end{array}$ \\
\hline TOTAL & & $\begin{array}{l}100 \%(24 \\
\text { fragmentos } \\
\text { textuais) }\end{array}$ \\
\hline
\end{tabular}

Fonte: Os autores. 
Reigota (2002) considera como uma representação social de meio ambiente essa forma de pensar e concebê-lo. Na noção naturalista o meio ambiente está atrelado ao conceito de natureza. Os fragmentos textuais unitarizados UR 1.1 (8,7\%) referem-se a essa noção naturalista de contemplação da natureza como bela, um lugar para ser preservado e admirado: " $A$ beleza das matas em harmonia. Todo esse encanto que contagia [...]" (L01). Esses estudantes transmitem nas letras musicais o resgate da ligação com a natureza e, dessa forma, deslocam sua relação com a sociedade para um plano mais afetivo, em que os sujeitos aprendam a amar a natureza e, consequentemente, a respeitá-la (SAUVÉ, 2005).

$\mathrm{Na}$ UR 1.2 Antropocêntrica $(21,8 \%)$ foram unitarizados os fragmentos textuais que mencionam o meio ambiente como um recurso que deve ser gerenciado para o bem-estar dos seres humanos. A discussão da crise ambiental, suas origens e consequências não se fazem presentes nessas letras, pois ao desconsiderar a interface social e os fatores históricos da crise ambiental, não se apresentam as raízes do problema (FONSECA, OLIVEIRA, 2011)

A preocupação central é com a garantia da sobrevivência do homem, "[...] aqui nesta Terra temos a água pra sustentar, economizando ela nunca vai nos faltar [...] [...] garantir nossa sobrevivência [...]" (L05). Historicamente a questão ambiental surge da visão do ser humano como sendo o centro do sistema, um ser superior, capaz de dominar e se apropriar da natureza, como nos fragmentos "[...] tudo o que construí pra tu poder usar [...]" (L08) e "[...] tirar o necessário. Sem exagerar. Usar a natureza [...]". (L15). Essas ideias proporcionam o desenvolvimento de uma visão fragmentada e excludente, contrapondo-se os processos naturais do ser humano como parte integrante da própria natureza (KIRST, 2010). Tal modelo de "usar a natureza" beneficia uma pequena parcela da sociedade, um modelo de crescimento econômico de extração de recursos naturais, de acumulação de capitais (GUIMARÃES, 2005).

Na UR 1.2 também foi observada a descrição do homem como o destruidor da natureza dada por Deus: "[...] não podemos destruir a nossa herança. Presença é virtude destruir nunca mais. É cuidar daquilo que Deus nos traz" (L01). A noção de meio ambiente como resultado de uma obra divina remete ao pensamento da Idade Média, em que o homem passa a assumir o papel de dominador, de modo que a natureza deve ser dominada.

As letras das músicas L01 e L05 foram unitarizadas na UR 1.1, e outras na UR 1.2, o que mostra a transição dualista entre a noção antropocêntrica e a naturalista.

Na UR $1.3(21,8 \%)$ percebe-se a multidimensionalidade (dimensão natural, social, político) do ambiente (MORIN, 2011; LEFF, 2003, 2006), como, por exemplo, no trecho "[...] pra que exportar tanto os nossos produtos, esgotando assim todos nossos recursos. Acidente nuclear grande 
contaminação [...] Centros urbanos, segregação social, lixos não renováveis, problema ambiental [...]'. (L11).

Os fragmentos textuais evidenciam a crise ambiental e outras preocupações que se tornam mais densas por conta das "ações transformadoras do homem no espaço, excessiva exploração da natureza, empobrecimento do solo, desigualdades sociais, miséria, poluição das águas, entre outros fatores, que contribuíram consideravelmente para este tipo de crise" (KIRST, 2010, p. 23).

O ambiente na UR 1.3 é percebido pelas relações dinâmicas e em interação entre elementos naturais e sociais, como quando estudantes descrevem "[...] pessoas pobres, sujas, sem comida, tratadas como bichos. [...] Pra vida, natureza, segurança e educação [...]" (L06) e "[...] Penso na Amazônia, Cerrado e Pantanal. Na Mata Atlântica, Araucária e Caatinga. Dando lugar pra soja e milharal. Nas estradas não cabem tanto carro [...]' (L07).

Além de implicar processos de criação cultural e tecnológica, essas relações pressupõem também processos históricos e sociais de transformação do meio natural em meio construído (REIGOTA, 2002). Trazem para as letras musicais a discussão do consumismo exagerado e da falta do olhar para com o outro e a mudança no estilo de vida: "[...] E vai comprando e vai comprando. $E$ vai juntando coisas e coisas. Nem se dá conta que. Que não precisa de tanta tralha para viver. Enquanto isso o meu vizinho, aquele menino bem magrinho. Vai procurar lá no meu lixo, um pouco de pão pra ele comer [...]" (L09). Guimarães (2007) descreve essa crise como sendo civilizatória, e não somente uma crise ecológica. Uma crise de um modelo de sociedade e seu modo de produção, como mencionado na música L09.

É interessante perceber adolescentes descrevendo por meio das composições musicais as relações entre o mundo natural e o social. Como menciona Carvalho (2006, p.82), essa indissociável interação resulta "nas condições de vida humana na Terra e as marcas dessa presença na natureza, as quais criam permanentemente, no mundo, novos cursos de vida, fluxos de comunicação e paisagens tanto naturais quanto culturais".

$\mathrm{Na}$ UR 1.4 Destruição foram unitarizados três fragmentos textuais (13\%) que descrevem a destruição do meio ambiente: "[...] Mas realmente a natureza humana é mesquinha. Destrói tudo sem pensar nas consequências [...]" (L08), "[...] O que resta é só lamento [...]" (L21). Essas músicas possuem um forte tom de denúncia, porém não relatam as interfaces culturais, sociais, econômicas e políticas que permeiam as relações entre homem e natureza.

Na UR 1.5 Problema/Solução foi unitarizada a maioria dos fragmentos textuais (30,4\%). Como afirma Sauvé (2003), o ambiente não é apenas um conjunto de problemas para resolver, mas acima de tudo um modo de vida para o qual se pode desenvolver um sentimento de pertença. Percebe-se em algumas letras musicais, de maneira explícita, o homem como o causador do problema: "[...] Os erros que gostamos de cometer [...]" (L03), "O homem

revista brasileira educação ambiental 
chegou. Desmatou. Poluiu. O rio ele contaminou. Na natureza interferiu. E a teia da vida. Quebrou [...]'. (L18).

Em muitas dessas letras que apresentam os problemas, as soluções são simplistas, basta fazer a nossa parte e os problemas se resolvem: "[...] Cada um de nós precisa fazer a sua parte. Recicle, cuide da água. Cuide do ar, proteja a natureza [...]" (L03), "[...] vamos separar o lixo. Precisamos reciclar. Proteger nossos bichos. Nem pensar em desmatar" (L04), "[...] devemos reciclar, preservar, cultivar, transformar [...]". (L19).

Sustentar-se na noção que considera o meio ambiente como natureza (UR1.1) e recurso (UR 1.2) é reduzi-lo ao espaço no qual acontecem as relações físicas, químicas e biológicas. É necessário pensar além, pensar na crise ambiental como crise cultural e de conhecimento, e não somente de gerenciamento da natureza.

$\mathrm{Na}$ unidade de registro emergente 1.6 reducionista, somente uma letra de música $(4,3 \%)$ foi unitarizada. Essa letra refere-se apenas à importância da reciclagem, no entanto não a correlaciona com outras questões importantes relacionadas à produção do lixo, não apresenta a multidimensionalidade desse assunto. Como mencionam Fonseca e Oliveira (2011, p.242), compreender a crise ambiental de uma maneira simplista implica "apostar em soluções que coadunam com essa mesma linha de pensamento, tais como a reciclagem, preservação das nascentes, produção de mudas, entre outros".

Pensar no meio ambiente numa perspectiva crítica é ir além de uma leitura biologizante (UR1.1), antropocêntrica (UR 1.2) e reducionista (URE1.6). É buscar entender as complexas inter-relações e conflitos de interesses que envolvem a sociedade e a natureza (UR1.3), e que resultam na atual crise ambiental vivenciada.

A partir desses resultados evidencia-se a necessidade da educação ambiental numa perspectiva crítica, transformadora, emancipatória, que reflita os conflitos socioambientais. Na escola, a perspectiva crítica poderia modificar noções naturalistas, antropocêntricas, de destruição, de problema/solução e reducionista para noções complexas que apresentem a multidimensionalidade da questão ambiental.

\section{Conclusões}

O processo de criatividade na composição musical precisa ser compreendido como um produto histórico-social, completamente inserido no tempo e espaço no qual se dá, a partir das condições objetivas do contexto, sempre mediado por um processo intersubjetivo (MAHEIRIE, 2003). Assim, ao pensarmos nas letras musicais apresentadas como noções de meio ambiente dos estudantes que as produziram, podemos criar meios para a reflexão em relação às interferências da escola nesse processo criativo. As questões que surgem, mas que não temos a pretensão de responder neste momento, são as seguintes: como os professores desses alunos concebem o meio ambiente e a 
educação ambiental? Qual a influência das noções de meio ambiente dos professores nas letras musicais? Como é o processo de composição das músicas? São utilizados meios de pesquisa? Quais? Mais do que respostas definitivas, o que não era nossa pretensão, a pesquisa ora apresentada nos abriu novos caminhos de investigação e nos mostrou que a música pode ser um excelente instrumento para as reflexões ambientais.

Consideramos que o objetivo desta pesquisa - analisar as noções de meio ambiente que estão explícitas nas composições musicais elaboradas por alunos do ensino médio para o festival da canção ecológica do ano de 2014 foi alcançado. Quanto às noções de meio ambiente, foi possível identificar a naturalista, a antropocêntrica, a complexa, a de destruição, a de problema/solução e a reducionista. Por meio da música os estudantes expressaram pensamentos, sentimentos e conhecimentos em relação ao meio ambiente, de uma maneira espontânea e criativa. Demonstraram suas preocupações com a crise ambiental, buscando maneiras de solucionar os problemas, inter-relacionando questões de ordem social, política, econômica e ecológica.

Por fim, vale refletir sobre a importância da música na vida dos jovens, reconhecendo que usá-la como um meio para discutir as questões ambientais é significativo, porém somos cientes da necessidade de mudanças, que devem ser pautadas numa perspectiva crítica. No momento em que os estudantes forem orientados na escola para a produção musical, poderão alcançar o entendimento da complexidade das questões ambientais inseridos em um contexto histórico que inclui seus fatores sociais, políticos, culturais e econômicos.

\section{Agradecimentos}

À Prefeitura Municipal de Guarapuava.

\section{Referências}

AIRES, B.F.C.; BASTOS, R.P. Representações sobre Meio Ambiente de alunos da Educação Básica de Palmas (TO). Ciência \& Educação, v. 17, n. 2, p. 353364, 2011.

BARDIN, L. Análise de conteúdo. Lisboa: Edições 70, 2004.

BOGDAN, R.; BIKLEN, S. Investigação qualitativa em educação: uma introdução à teoria e aos métodos. Portugal: Porto, 1994.

BRÜGGER, P. Educação ou adestramento ambiental? 3. ed. rev. Chapecó: Letras Contemporâneas, 2004.

CARVALHO, I.C.M. Educação ambiental: a formação do sujeito ecológico. 2. ed. São Paulo: Cortez, 2006 (Coleção Docência em formação). 
DIAS, G.F. Educação Ambiental: Princípios e Práticas. São Paulo: Gaia Ltda., 2004, p. 551.

FONSECA, F.S.R.; OLIVEIRA, L.G. Concepções de meio ambiente dos educadores ambientais do Zoológico de Goiânia: implicações nas atividades e contribuições para a formação do sujeito ecológico? Educar em Revista, n. 41, p. 231-246, jul./set., 2011.

GARRIDO, L.S.; MEIRELLES, R.M.S. Percepção sobre meio ambiente por alunos das séries iniciais do Ensino Fundamental: considerações à luz de Marx e de Paulo Freire. Ciência e Educação, Bauru, v. 20, n. 3, p. 671-685, 2014.

GUIMARÃES, M. Educação ambiental: participação para além dos muros da escola. In: MELLO, S.S.; TRAJBER, R. (Coord.). Vamos cuidar do Brasil: conceitos e práticas em educação ambiental na escola. Brasília: Ministério da Educação: Ministério do Meio Ambiente: UNESCO, 2007. p. 85-93.

GUIMARÃES, M. A dimensão ambiental na educação. 7. ed. Campinas: Papirus, 2005.

GUIMARÃES, M. Educação ambiental crítica. In: LAYRARGUES, P.P. (Org.). Identidades da educação ambiental brasileira. Brasília: Ministério do Meio Ambiente, 2004. p. 25-34.

IARED, V.G.; OLIVEIRA, H.T. Concepções de Educação Ambiental e perspectivas pedagógicas de professoras do ensino fundamental. Educação em Revista. Belo Horizonte, v.27, n.02, p.95-122 ago., 2011.

KIRST, A.C.F. Concepções e práticas de Educação Ambiental: uma análise a partir das matrizes teóricas e epistemológicas presentes em escolas estaduais de Ensino Fundamental de Santa Maria-RS. 2010. 135f. Dissertação (Mestrado em Geografia). Universidade Federal de Santa Maria, Santa Maria, 2010.

LEFF, H. (Coord.). A complexidade ambiental. São Paulo: Cortez, 2003.

LEFF, H. Epistemologia ambiental. São Paulo: Cortez, 2006.

LIMA, A.M.; OLIVEIRA, H.T.A (re) construção dos conceitos de natureza, meio ambiente e educação ambiental por professores de duas escolas públicas. Ciência \& Educação. Bauru, v. 17, n. 2, p. 321-337, 2011.

LOUREIRO, C.F.B. Educação Ambiental transformadora. In: LAYRARGUES, P.P.(Org.). Identidades da Educação Ambiental brasileira. Brasília: MMA, 2004. p. 65-84.

LÜDKE, M.; ANDRÉ, M.E.D.A. Pesquisa em educação: abordagens qualitativas. 10. ed. São Paulo: EPU, 1986, p. 99.

MAGALHÃES Júnior, C.A.O.; TOMANIK, E. A. Representações Sociais de Meio Ambiente: subsídios para a formação continuada de professores. Ciência \& Educação, v. 19, n. 1, p. 181-199, 2013. 
MAHEIRIE, K. Processo de criação no fazer musical: uma objetivação da subjetividade, a partir dos trabalhos de Sartre e Vygotsky. Psicologia em Estudo, Maringá, v. 8, n. 2, p. 147-153, 2003.

MARTINHO, L.R.; TALAMONI, J.L.B. Representações sobre meio ambiente de alunos da quarta série do Ensino Fundamental. Ciência \& Educação, v. 13, n. 1, p. 1-13, 2007.

MORIN, E. Os sete saberes necessários à educação do futuro. 3. ed. São Paulo: Cortez; Brasília, DF: UNESCO, 2011.

NETO, A.L.G.C.; AMARAL, E.M.R. Análise de concepções e visões de professores de ciências sobre educação ambiental. Pesquisa em Educação Ambiental. vol. 6, n. 2 - pp. 119-136, 2011.

NUNES, T.R. A influência da música sobre as representações sociais de meio ambiente no contexto de uma exposição científica. 2005. 156f. Dissertação de Mestrado. Universidade Federal de Santa Catarina, 2005.

REIGOTA, M. O que é Educação Ambiental. São Paulo: Brasiliense, 2006, p. 62.

REIGOTA, M. Meio ambiente e representação social. São Paulo: Cortez, 2002.

SAUVÉ, L. Uma cartografia das correntes em educação ambiental. Tradução de Ernani Rosa. In: SATO, M.; CARVALHO, I.C.M.(Org.). Educação ambiental: pesquisa e desafios. Porto Alegre: Artmed, 2005. cap. 1, p. 17-44.

SAUVÉ, L. (Org.). Perspectivas curriculares para la formación de formadores en educación ambiental. In: Foro nacional sobre la incorporación de la perspectiva ambiental en la formación técnica y profesional, 1, 2003, San Luis Potosi. Memoria... San Luis Potosi: UASLP, 2003. p. 1-20. 